\title{
Produção orgânica de calêndula: um estudo de caso
}

\author{
Organic production of marigold: a case study
}

Elder Tschoseck Borba ${ }^{\mathrm{I}}$ Birgit Harter-Marques ${ }^{\mathrm{II}}$ Vanilde Citadini-Zanette ${ }^{\mathrm{I}}{ }^{*}$

RESUMO

Apresenta-se caracterização do processo de produção agrícola orgânica de Calendula officinalis $L$. no Estado de Santa Catarina, evidenciando particularidades e discrepâncias frente aos modelos já descritos na literatura especializada, a partir de visitas a campo, observação participante e entrevistas com um produtor de plantas medicinais. Identificaram-se como principais particularidades a saúde na agricultura familiar, demonstrada pela prática da cultura orgânica, além do controle de pragas e manuseio da produção. Os principais problemas ou divergências evidenciados foram: características do solo; época de plantio da calêndula e suas etapas posteriores, como transplante e floração. Aspectos da colheita foram discrepantes quanto ao período do dia indicado para o procedimento, bem como a ausência de informações do produtor quanto à existência de outros incentivos governamentais ao setor agrícola. Recomenda-se aos extensionistas rurais e/ou instituições competentes que busquem orientar os produtores orgânicos de calêndula para promover a adequação das práticas de cultivo dessa espécie medicinal.

Palavras-chave: Calendula officinalis L., Asteraceae, planta medicinal, agricultura familiar, cultivo orgânico.

\section{ABSTRACT}

A characterization of the process of organic agriculture production of Calendula officinalis $L$. in the State of Santa Catarina is presented, evidencing particularities and discrepancies contrasting to the models already described in specialized literature, by field visits, participative observations and interviews with a medicinal plant producer. The main particularities identified were the health in the agricultural family, demonstrated by the practice of organic culture, besides pest control and the handling of production. The main evidenced problems or divergences were: soil characteristics; period of the marigold planting and its following stages, such as transplanting and flowering. Aspects of the crop were conflicting as for the period of the day indicated for the procedure, as well as the absence of information from the producer about the existence of other government incentives to the agricultural section. It is recommended to the rural extensions and/or competent institutions to seek for guiding the organic producers of marigold to promote adequate practices for the cultivation of this medicinal species.

Key words: Calendula officinalis L., Asteraceae, medicinal plant, family agriculture, organic crop.

\section{INTRODUÇÃO}

Calendula officinalis L. (Asteraceae), popularmente conhecida por calêndula, malmequer, entre outros nomes (SILVAJUNIOR, 2006), é cultivada em todo o mundo, inclusive no Brasil, devido as suas propriedades medicinais e potencial ornamental (BERTONI et al., 2006). Suas flores são utilizadas em forma de chá, compressas ou extratos contra afecções dermatológicas, com ação antipruriginosa, antiinflamatória e cicatrizante, fazendo parte da composição de preparações de medicamentos para tratamento de eritemas solares, queimaduras e dermatoses secas (SIMÕES, 2003; PAGNANO et al., 2008). Outros usos estão relacionados à ação anti-inflamatória e antiulcerogênica no tratamento de inflamações do trato digestivo superior (KÖRBES, 1995; MULEY et al., 2009).

'Programa de Pós-graduação em Ciências Ambientais (PPGCA), Unidade Acadêmica de Humanidades, Ciências e Educação (UNAHCE), Universidade do Extremo Sul Catarinense (UNESC), 88806-000, Criciúma, SC, Brasil.

"IPPGCA, UNAHCE, UNESC, Criciúma, SC, Brasil. E-mail: vcz@unesc.net. *Autor para correspondência. 
O desafio das agroindústrias que utilizam a calêndula, assim como outras espécies medicinais, é obter produção organizada na quantidade e qualidade necessárias, com fornecimento regular (ALTMANN, et al., 2008). Via de regra, no segmento de plantas medicinais, há falta de uma política pública de desenvolvimento tecnológico a partir de pesquisa participativa que valorize e resgate o conhecimento local e tradicional.

Atualmente, as plantas medicinais têm chamado a atenção por parte dos pesquisadores. Entretanto, o setor agronômico ainda precisa obter maiores informações sobre seu cultivo, sendo que a busca dessas informações, úteis para a padronização de materiais a serem utilizados, faz-se necessária diante da ausência de programas de melhoramento específicos para as plantas medicinais (VIEIRA et al., 2006).

No Brasil, o ramo da agricultura familiar representa $85,2 \%$ do total dos estabelecimentos, os quais ocupam 30,5\% da área total e são responsáveis por 37,9\% do Valor Bruto da Produção Agropecuária Nacional, segundo dados do INCRA. Em Santa Catarina, a agricultura é tipicamente familiar, pois corresponde a $90,5 \%$ dos estabelecimentos, sendo que os agricultores possuem $60 \%$ da área agrícola e respondem por 71,3\% do Valor Bruto da Produção Agropecuária Catarinense. Além disso, muito embora seja responsável pela produção da maioria dos alimentos, a agricultura familiar é a menos remunerada na maioria das situações em razão da falta de agregação de valor (BEREZANSKI, 2008).

Quanto às plantas medicinais, seu cultivo se transformou em uma fonte de renda para os produtores rurais. Sua inserção no campo dos “agronegócios”, muito embora tenha ocorrido de forma lenta, mostra-se em gradativa expansão, como uma atividade agrícola de expressão econômica, em razão do aumento da demanda por produtos naturais com potenciais terapêuticos.

Nessa perspectiva, apresentam-se resultados de estudo de caso sobre o cultivo orgânico de Calendula officinalis L., realizado no município de Grão-Pará, Estado de Santa Catarina, evidenciando particularidades e discrepâncias frente aos modelos de cultivo já descritos na literatura. Dessa forma, espera-se contribuir para o melhor entendimento desta cultura no contexto local, evidenciando erros e omissões que podem estar comprometendo a maximização de rendimento, bem como a qualidade final do produto a ser comercializado.

\section{MATERIAL E MÉTODOS}

O estudo de caso foi realizado com um produtor pioneiro no cultivo ecológico de plantas medicinais de uma propriedade particular localizada na zona rural do município de Grão-Pará (28¹3’58,7” S e 49¹7’58,9” W, altitude 93m - sede). A propriedade está inserida em uma região predominantemente produtora de fumo, circundada por remanescentes de Floresta Ombrófila Densa Submontana. O clima do município, segundo a classificação climática de Koeppen, é Cfa - mesotérmico úmido, com verão quente e sem estação seca definida. Apresenta temperatura média anual de $19,2^{\circ} \mathrm{C}$ e índice pluviométrico médio entre $1.300 \mathrm{~mm}$ a $1.500 \mathrm{~mm}^{-1}$ ano ${ }^{-1}$ As geadas são constantes no inverno e a cobertura vegetal original era de Floresta Ombrófila Densa (PREFEITURA MUNICIPALDE GRÃO-PARÁ, 2009).

Apenas um produtor de plantas medicinais foi contatado por deter maior conhecimento sobre o cultivo e produção da calêndula e ser um dos poucos fornecedores desta espécie na região sul do Estado. O levantamento de dados incluiu visitas a campo, uso de técnicas de observação participante e entrevistas semiestruturadas (ALBUQUERQUE et al., 2010). As perguntas das entrevistas foram elaboradas com o objetivo de obter informações sobre a origem do produtor e suas atividades desenvolvidas antes do início da produção de plantas medicinais. Buscou-se caracterizar o histórico da produção, utilização da planta pela família, sistema de plantio, controle de pragas, produção e comercialização, a renda do produtor e incentivos governamentais referentes à calêndula. Os dados obtidos foram comparados com as informações disponíveis na literatura especializada, para detectar discrepâncias e/ou particularidades sobre a planta.

\section{RESULTADOS E DISCUSSÃO}

Inicialmente, o produtor rural relatou que seus pais e avós já eram agricultores, tendo como atividade principal a plantação de mandioca. Quando tinha 13 anos de idade, foi dado início ao cultivo de fumo, produto que apresentava significativo valor rentável a sua família. A partir de 1987, deixou de trabalhar com o seu pai e passou a residir no município de Grão-Pará, SC, numa propriedade com área aproximada de 22,4 hectares, na qual, até meados de 1995, desenvolveu o cultivo intenso de fumo, juntamente com sua esposa e filhos. Com a plantação de fumo passaram a ter problemas de saúde, relacionados à utilização de agrotóxicos em grande quantidade, ocasionando o abandono da cultura do fumo em sua propriedade.

Diante do diagnóstico de intoxicação, foi sugerida pelo médico a utilização de uma cultura sem agrotóxicos, o que o levou ao cultivo de ervas medicinais, uma vez que, na região, apenas uma pequena família do 
município de São Ludgero, SC, trabalhava com essa cultura, de onde obteve as primeiras sementes de $\boldsymbol{C}$. officinalis. Conforme informações relatadas pelo agricultor, foi esse o motivo incentivador para o início do plantio orgânico em toda sua propriedade, para obtenção de melhor qualidade de vida.

Atualmente, do total da área produtiva, aproximadamente três hectares ou 13,3\% da área total são reservados para o cultivo de plantas medicinais, tais como calêndula, camomila, funcho, alcachofra, maracujá, hortelã, melissa, cana-cidreira, entre outras. O restante da área é utilizado, principalmente, para plantação de milho, feijão, alho e laranja.

Sobre os conhecimentos das plantas medicinais, o produtor informou que possui formação escolar até a “quarta série primária”, porém sempre se interessou sobre o assunto, lendo livros específicos, participando de cursos promovidos pela Pastoral da Saúde e eventos relacionados, buscando também orientações junto à Empresa de Pesquisa Agropecuária e Extensão Rural de Santa Catarina (EPAGRI). Ressaltase que atualmente a EPAGRI incentiva a produção de plantas medicinais, disponibilizando palestras, seminários e treinamento para produtores e técnicos sobre o tema (SILVA JÚNIOR, 2010).

Em 2007, o produtor obteve certificação de origem e manejo orgânico junto à Associação de Agricultura Orgânica (AAO), tendo sua produção principal destinada ao comércio em estabelecimentos de produtos naturais e laboratórios de fitoterápicos. A certificação do produtor orgânico é um pré-requisito para o acesso ao crédito. Desde 1999, o Banco do Brasil disponibiliza um plano de financiamento para a agricultura orgânica, valendo-se para isso principalmente de recursos do Programa Nacional de Fortalecimento da Agricultura Familiar (PRONAF). Dentro desse Programa, destaca-se a linha PRONAF Agroecologia, que tem como beneficiários os agricultores familiares enquadrados no PRONAF, desde que apresentem proposta simplificada ou projeto técnico estruturado, de acordo com as normas estabelecidas pelo Ministério de Desenvolvimento Agrário (MDA, 2012).

A cultura orgânica tem se destacado como uma das alternativas de renda para os pequenos agricultores, devido à crescente demanda mundial por alimentos mais saudáveis. Por sua vez, a menor dependência de insumos externos está associada, principalmente, à maior facilidade de manejo dos sistemas produtivos com recursos da propriedade (fertilizantes orgânicos, produtos naturais para controle fitossanitário, controle biológico natural, tração animal, combustíveis não-fósseis, entre outros) (CAMPANHOLA \& VALARINI, 2001).
Questionado sobre a utilização da calêndula pela família, o agricultor mencionou que a planta tem sido pouco aproveitada, sendo somente empregada em ferimentos expostos devido as suas propriedades “curativas e cicatrizantes”, auxiliando na prevenção de infecções. As inflorescências são maceradas e aplicadas no local do ferimento na forma de emplasto. A utilização popular da calêndula se deve pelas suas propriedades colerética, anti-inflamatória, analgésica, antitumoral, bactericida, diurética, cicatrizante, sedativa e imunomoduladora (FRANCO, 1996), sendo que estudos científicos comprovam a propriedade antiinflamatória dessa espécie, corroborando a indicação popular (HEROLD et al., 2003; UKIYA et al., 2006; MULEY et al., 2009).

Questionado sobre o sistema de plantio, o agricultor deu seu parecer aos pontos positivos do tipo de cultivo utilizado, relatando: “[...] faço a semeadura de forma aleatória e, quando chega a estação de florescência, eu faço colheita todos os dias. Se passar do dia, as flores caem com suas sementes e, na próxima estação, haverá mais indivíduos desta espécie plantada naturalmente”. Conforme constatado, o produtor utiliza o sistema de replantio natural na horta, que indica a existência de um ambiente propício para o desenvolvimento das plantas medicinais, não exigindo o plantio em canteiros organizados, bastando apenas a existência de um ambiente favorável, o que tem proporcionado, segundo ele, inúmeros benefícios, dentre eles a previsibilidade, associada à ausência de riscos relativos ao tempo exato da colheita, como exemplifica, o que leva a crer, devido às características descritas, na existência do "policultivo".

Dessa maneira, a forma de cultivo das plantas medicinais utilizada pelo produtor entrevistado pode ser considerada como prática de agroecologia, voltada para o cultivo orgânico e assegurada por um controle biológico eficiente, o que pode ser verificado diante do resultado positivo da produção agrícola. Esse tipo de cultura proporciona meios viáveis para desenvolver uma agricultura ambientalmente correta e produtiva, valorizando o conhecimento empírico do local de cultivo e sua aplicabilidade para alcançar a sustentabilidade (GLIESSMAN, 2009).

Merece destaque a utilização do modelo de “policultivo", como meio de redução da população de pragas, o que tem proporcionado a redução do nível de ataque às plantas, comparado ao monocultivo tradicional e, consequentemente, uma maior produtividade por área plantada (VEIGA SILVA, 2009).

Explicando resumidamente as etapas de plantio da calêndula, o produtor informou que primeiramente é feita a semeadura por volta do mês de 
junho, utilizando-se as sementes obtidas da colheita do ano anterior. Entretanto, destaca que "a calêndula não precisa ser plantada, o banco de sementes já está no solo. Não colhidas todas as flores, elas caem e se semeiam”. Muito embora a literatura indique como época de plantio os meses de março a maio (SILVA JUNIOR, 2006; VAZ \& JORGE, 2006), tal procedimento é realizado pelo produtor entre os meses de julho e agosto, posteriores à semeadura realizada em junho, uma vez que as mudas são transplantadas 30 a 35 dias após essa data. O produtor relatou, ainda, que a calêndula não é exigente quanto ao solo para o plantio. No entanto, SILVAJUNIOR (2006) menciona que a planta prefere solos férteis, médios, drenados, permeáveis e ricos em matéria orgânica.

Segundo o agricultor, após as mudas crescerem e obterem aproximadamente cinco folhas cada uma, são transplantadas de forma direta para canteiros definitivos e distribuídas no espaçamento de $60 \mathrm{~cm}$ entre linhas e $40 \mathrm{~cm}$ entre plantas.

Recomenda-se que a colheita tenha início entre dois a três meses após o plantio, prolongando-se por mais dois meses, devendo ser realizada periódica e preferencialmente no período vespertino, podendo produzir até $720 \mathrm{~kg} \mathrm{ha}^{-1}$ (SILVAJUNIOR, 2006; VIEIRA et al., 2006). Esse procedimento tem sido respeitado pelo produtor, que realiza a colheita no início da florada por, no mínimo, duas vezes na semana, enfatizando que o pico da colheita é um mês após o replantio, que é realizado em agosto, sendo, portanto, a colheita realizada em setembro. Importante ressaltar a observação feita pelo agricultor quanto à colheita das ervas medicinais, no sentido de que "cada erva tem um turno diferente do outro, por exemplo: as ervas que se usam as folhas e/ou flores, colho pela manhã; as ervas que se utilizam as raízes e/ou caule, colho à tarde”. Conforme orientações obtidas pelo agricultor junto à Pastoral da Saúde, a colheita da calêndula deve ser realizada no período matutino, devido à maior quantidade de compostos (princípios ativos) presentes nas flores neste turno do dia.

Após colhidas, todas as ervas sofrem o mesmo procedimento de secagem, sendo colocadas em bandejas dentro da estufa de alvenaria, com fluxo de ar contínuo, à temperatura controlada, não ultrapassando $40^{\circ} \mathrm{C}$, mantida por meio de aquecimento à lenha, cujo tempo de permanência varia conforme a espécie. As flores da $\boldsymbol{C}$. officinalis são mantidas na estufa por seis a sete dias. Tal procedimento ratifica estudos de LUZ et al. (2001), cuja indicação para secagem é de sete a dez dias. Após desidratadas, o armazenamento é feito em embalagens de plástico, com capacidade aproximada de 2 a $4 \mathrm{~kg}$, tendo o cuidado para não ultrapassar o tempo de estocagem, sob risco de perda do produto.

Outro fator que o produtor mencionou como importante foi o excesso de chuva, que tem prejudicado a plantação da calêndula, impedindo seu crescimento e favorecendo aumento de doenças e proliferação de pragas. Essa informação corrobora o trabalho de SILVA JUNIOR (2006), que observou que o excesso de chuvas pode afetar drasticamente a produção de sementes, principalmente quanto à baixa qualidade.

Com relação ao controle das pragas existentes na lavoura, o agricultor considera que, se o ambiente for equilibrado "a biodiversidade dá conta de tudo”, ou seja, “quando” e "se aparecem”, sejam elas microscópicas ou não, apresentam-se em quantidades tão insignificantes que não influenciam de forma negativa no plantio. Quando necessário, utiliza sulfato de cobre com cal (calda bordalesa) ou chá de camomila, que funciona como antifúngico e fortificante. Nesse contexto, importante informação do agricultor merece destaque ao afirmar que "as calêndulas em presença da camomila adoecem menos”. Sabemos que a camomila funciona como fungicida, protegendo as calêndulas contra fungos. "[...] havia um pé de calêndula e outro de camomila juntos, quando a camomila secou a calêndula adoeceu”. Fato similar comprova a ação da camomila em determinadas espécies de fungos que atacam as frutas pós-colheita. Em laboratório, foi avaliado o efeito fungitóxico de algumas plantas medicinais e aromáticas, entre elas, a camomila, acreditando que poderia haver alguma ação contra os fungos Glomerella cingulata e Colletotrichum gloeosporioides, causadora da antracnose em goiaba (Psidium guajava L.). Constatou-se que a camomila, preparada em decocto, deteve grande controle biológico de $\boldsymbol{C}$. gloeosporioides, indicando sua aplicação como controle alternativo contra antracnose (ROZWALKA, 2008).

Conforme informado pelo produtor, o plantio de $\boldsymbol{C}$. officinalis é feito conforme os pedidos efetuados por compradores dos municípios catarinenses de Criciúma, Gravatal, São José, Florianópolis e região, sendo comercializadas somente as flores, utilizadas para fins estéticos (cosmecêutica), laboratoriais, farmácias de manipulação e de homeopatia. Segundo SILVA JÚNIOR (2006), a produção de calêndula no Estado de Santa Catarina é voltada para o mercado interno, destinada ao comércio regional, estadual e nacional, sendo uma das espécies mais utilizadas em cosmecêutica.

Na propriedade estudada, verificou-se que a produção anual de calêndula desidratada corresponde a $10 \mathrm{~kg} \mathrm{ha}^{-1}$. As flores desidratadas são 
vendidas pelo valor de $\mathrm{R} \$ 20,00 \mathrm{~kg}^{-1}$, sendo os preços ajustados conforme os custos com insumos, tais como embalagens, energia elétrica, entre outros. No estado de Santa Catarina, tem-se conhecimento de que a produção anual de calêndula chega a $80 \mathrm{~kg} \mathrm{ha}^{-1} \mathrm{ano}^{-1}$, sendo a região Sul responsável por $20 \mathrm{~kg} \mathrm{ha}^{-1} \mathrm{ano}^{-1} \mathrm{e} \mathrm{a}$ produção é comercializada por aproximadamente $\mathrm{R} \$ 10,00$ base seca (SILVAJUNIOR, 2006).

O produtor relatou que sua lavoura de plantas medicinais gera um ganho líquido anual no valor de aproximadamente $\mathrm{R} \$ 5.000,00$, sendo que suas despesas com a produção são mínimas, já que não despende qualquer valor com energia para a estufa (pois a lenha é retirada de sua propriedade), com sementes (que não precisam ser compradas) e nem mesmo com fertilizantes, diferentemente do cultivo do fumo, que, muito embora seja mais lucrativo, envolve despesas maiores. Assim sendo, o cultivo de plantas medicinais se apresenta como um complemento de renda para o produtor, visto que não depende única e exclusivamente da venda desses produtos para o sustento de sua família, o qual é garantido pela produção de gêneros alimentícios.

Sobre o recebimento de incentivo governamental para o desenvolvimento agrícola, o produtor informou que atualmente não recebe auxílio algum. Porém, em dezembro de 2005, a família recebeu a quantia de R\$2.100,00 do Governo Federal a título de “crédito de fundo perdido". Complementou que apenas recebe orientações da EPAGRI, incentivando o plantio natural sem agrotóxicos. Salienta-se que atualmente o governo dispõe de instrumentos de apoio aos agricultores familiares por meio do crédito rural, cujo objetivo é possibilitar a introdução e uso de tecnologias modernizadas no setor agrícola, sendo o PRONAF a principal fonte de recursos financeiros, tais como linhas de ação para custeio, investimentos e infraestrutura (TREVISAN, 2007).

\section{CONCLUSÃO}

Pelo estudo etnobiológico realizado com um produtor rural de plantas medicinais, com ênfase à calêndula, constatou-se que o contexto abordado apresenta a figura de um "ator social” que, sendo a base de uma cultura de subsistência e preocupado com a qualidade de vida da família, principalmente quanto à saúde que se encontrava fragilizada em decorrência do cultivo de fumo, optou por dar início à produção orgânica em sua propriedade, com ênfase na produção de plantas medicinais. A curiosidade do agricultor o levou a obter conhecimentos específicos sobre as plantas medicinais, o que até então era desconhecido por ele, destacando-se a não utilização de fertilizantes químicos ou até mesmo de herbicidas em sua lavoura.

Verificou-se que a atividade rural desenvolvida na propriedade enfocada tem como fundamento a família, responsável por todas as etapas da produção agrícola, voltada ao plantio de mantimentos, coleta e beneficiamento primário de seus produtos, baseadas no trabalho familiar, sendo boa parte da produção destinada à comercialização. Ressalta-se que a produção de plantas medicinais como meio de renda ao pequeno agricultor ainda é relativamente baixa, já que conta com uma renda aproximada de 10 salários mínimos anuais. A situação enfrentada pelas famílias que dependem da agricultura familiar tem desestimulado o investimento pelos pequenos produtores na área, o que seria diferente se os incentivos e subsídios concedidos pelo governo fossem mais atrativos e concessivos, o que demandaria um aumento de interesse por parte dos agricultores. Em decorrência, haveria uma expansão da cadeia produtiva com valorização (ganho) em todas as etapas.

\section{COMITÊ DE ÉTICA E BIOSSEGURANÇA}

O projeto intitulado "Etnobiologia e investigação da influência dos insetos sobre a atividade anti-inflamatória e analgésica de Calendula officinalis L. (Asteraceae) em camundongos” foi aprovado pelo Comitê de Ética em Pesquisa da Universidade do Extremo Sul Catarinense - UNESC, parecer n.93/2010.

\section{REFERÊNCIAS}

ALBUQUERQUE, U.P. de et al. Métodos e técnicas para coleta de dados etnobiológicos. In: ALBUQUERQUE, U.P. de et al. Métodos e técnicas na pesquisa etnobiológica e etnoecológica. Recife: NUPPEA, 2010. p.39-64.

Altmann, R. et al. Perspectivas para o sistema agroalimentar e o espaço rural de Santa Catarina em 2015: percepção de representantes de agroindústrias, cooperativas e organizações sociais. Florianópolis: Epagri, 2008. 133p

BEREZANSKI, I. Agricultura familiar: ameaças e oportunidades. Florianópolis: SEBRAE/SC, 2008. Disponível em: <http:// www.sebraesc.com.br/newart/default.asp?materia=16289>. Acesso em: 15 out. 2010

BERTONI, B.W. et al. Micropropagação de Calendula officinalis L. Revista Brasileira de Plantas Medicinais, Botucatu, v.8, n.2, p.48-54, 2006. Disponível em: <http:// www.ibb.unesp.br/servicos/publicacoes/rbpm/pdf_v8_n2_2006/ artigo9_v8_n2.pdf>. Acesso em: 04 jun. 2010.

CAMPANHOLA, C.; VALARINI, P.J. A agricultura orgânica e seu potencial para o pequeno agricultor. Cadernos de Ciência \& Tecnologia. Brasília, v.18, n.3, p.69-101, 2001. Disponível em: <http:/ /www.ipcp.org.br/storage/EA/Alimenta\%E7\%E3o\%20e\% 20Agricultura\%20Org\%E2nica/AGRICULTURA\%20ORG\% C2NICA\%20E\%20SEU\%20POTENCIAL \%20para\%20pequena \%20produtores.pdf>. Acesso em: 15 jul. 2010. 
FRANCO, L.L. As sensacionais $\mathbf{5 0}$ plantas medicinais campeãs de poder curativo. Curitiba: Santa Mônica, 1996. 241p.

GLiessman, S. Agroecologia: processos ecológicos em agricultura sustentável. Porto Alegre: UFRGS, 2009. 654p.

HEROLD, A. et al. Hydroalcoholic plant extracts with antiinflammatory activity. Roumanian Archive of Microbiological Immunology, v.62, n.1-2, p.117-129, 2003.

KÖRBES, V.C. Plantas medicinais. Francisco Beltrão: Associação de Estudos, Orientação e Assistência Rural, 1995. 186p.

LUZ, L.A. de la et al. Instructivo Técnico de Calendula officinalis. Revista Cubana de Plantas Medicinais, v.1, p.23-27, 2001.

MDA - Ministério do Desenvolvimento Agrário. Crédito Rural PRONAF. Brasília, 2012. Disponível em: <http:// www.mda.gov.br/portal/saf/programas/pronaf $>$. Acesso em: 28 mar. 2012.

MULEY, B.P. et al. Phytochemical constituents and pharmacological activities of Calendula officinalis Linn. (Asteraceae): a review. Tropical Journal of Pharmaceutical Research, v.8, n.5, p.455-465, 2009. Disponível em: <http:/ /www.tjpr.org/vol8_no5/2009_8_5_11_Muley.pdf>. Acesso em: 05 ago. 2010.

PAGNANO, L. de O. et al. Morfometria de fibroblastos e fibrócitos durante o processo cicatricial na pele de coelhos da raça Nova Zelândia Branco tratados com calêndula. Ciência Rural, v.38, n.6, p.1662-1666, 2008. Disponível em: <http:/ /www.scielo.br/pdf/cr/v38n6/a26v38n6.pdf>. Acesso em: 18 ago. 2010. doi: 10.1590/S0103-84782008000600026.

PREFEITURA MUNICIPAL DE GRÃO PARÁ. Disponível em: <http://www.graopara.sc.gov.br/conteudo/?item=13646\&fa=3889>. Acesso em: 09 jun. 2009.

ROZWALKA, L.C. et al. Extratos, decoctos e óleos essenciais de plantas medicinais e aromáticas na inibição de Glomerella cingulata e Colletitrichum gloeosporioides de frutos da goiaba. Ciência Rural, v.38, n.2, p.301-307, 2008. Disponível em: $<$ http://www.scielo.br/scielo.php?script=sci_arttext\&pid=S0103$84782008000200001 \&$ lng=en \&nrm=iso $>$. Acesso em: 16 jul. 2010. doi: 10.1590/S0103-84782008000200001.

SILVA JUNIOR, A.A. Essentia herba-plantas bioativas. Florianópolis: Epagri, 2006. 663p.

SIMÕES, C. M.O. Farmacognosia: da planta ao medicamento. Porto Alegre: UFRGS, 2003. 1102p.

TREVISAN, A. Programas de apoio e linhas de crédito para agricultura familiar no Estado de Santa Catarina. Florianópolis: EPAGRI, 2007. 40p.

UKIYA, M. et al. Anti-inflammatory, anti-tumor-promoting, and cytotoxic activities of constituents of marigold (Calendula officinalis) flowers. Journal of Natural Products, v.69, n.12, p.1692-1696, 2006.

VAZ, A.P.A.; JORGE, M.H.A. Calêndula. Corumbá: EMBRAPA, 2006. 2p. (Série Plantas Medicinais, Condimentares e Aromáticas).

VEIGA SILVA, J.C.B. Comparação do desempenho de mono e policultivos orgânicos no rendimento das culturas, uso eficiente da terra e nos aspectos operacional e econômico. Revista Brasileira de Agroecologia, v.4, n.2, p.3661-3664, 2009. Disponível em: <http://www.aba-agroecologia.org.br/ojs2/index.php/ rbagroecologia/issue/view/46>. Acesso em: 15 set. 2010.

VIEIRA, M.C. et al. Crescimento e produção de biomassa de calêndula (Calendula officinalis L.) proveniente de dois tipos de diásporos e duas colorações de capítulos florais. Revista Brasileira de Plantas Medicinais, v.8, n.4. p.193-197, 2006. Disponível em: <http:/www.ibb.unesp.br/servicos/publicacoes/ rbpm/pdf_v8_n4_2006/artigo37_v8_n4_p193-197.pdf $>$. Acesso em: 11 out. 2010. 